\title{
Comparative study between proximal femoral nailing and dynamic hip screw with proximal femoral locking compression plates in intertrochanteric fracture of femur
}

\author{
Prasad Veeragandham ${ }^{1}$, Ramesh Kumar Sahu², Subarna Misra ${ }^{1}$
}

\begin{abstract}
${ }^{1}$ Department of Orthopedics, ${ }^{2}$ Department of Radiodiagnosis, ICARE Institute of Medical Sciences and Research, Banbishnupur, Purba Medinipur, Haldia, West Bengal, India
\end{abstract}

Received: 15 February 2017

Revised: 23 February 2017

Accepted: 28 February 2017

\author{
*Correspondence: \\ Dr. Prasad Veeragandham, \\ E-mail: drrameshsahoo251@gmail.com
}

Copyright: (C) the author(s), publisher and licensee Medip Academy. This is an open-access article distributed under the terms of the Creative Commons Attribution Non-Commercial License, which permits unrestricted non-commercial use, distribution, and reproduction in any medium, provided the original work is properly cited.

\section{ABSTRACT}

Background: Intertrochanteric fractures occur in people with poor bone quality, about half of the intertrochanteric fractures are comminuted and unstable. The purpose of the present study was to compare the outcome of surgical treatment of proximal femoral fracture by dynamic hip screw (DHS), proximal femoral nail (PFN) and proximal femoral locking compression plate (PFLCP).

Methods: This prospective comparative observational study had included cases presented with intertrochanteric fractures of femur attended orthopedic OPD and emergency department were treated with dynamic hip screw (DHS), proximal femoral nailing (PFN) or proximal femoral locking compression plate. Post-operative x-rays were done to assess reduction and progress of union (non-union/mal-union), any post-operative complications e.g. operative wound infection, implant failure etc.

Results: In our study, we found that PFNs prove to be more useful in difficult fractures with a subtrochanteric extension or reversed obliquity. The rotational stability was higher when proximal femoral nail is used in these fractures. The incidence of wound infection was found to be lower with intramedullary implants which resulted in early ambulation of the patients.

Conclusions: In our study, we found that proximal femoral nails prove to be more useful in difficult fractures with a sub-trochanteric extension or reversed obliquity. The rotational stability was higher when PFN is used in these fractures. The incidence of wound infection was found to be lower with intramedullary implants which resulted in early ambulation of the patients. Non-union of trochanteric fracture although is a rare entity.

Keywords: Intertrochanteric fracture of femur, Proximal femoral nailing, Dynamic hip screw, Proximal femoral locking compression plates, Outcome

\section{INTRODUCTION}

Trochanteric fractures are common in the elderly people. The frequency of these fractures has increased primarily due to the increasing life span and more sedentary life style brought on by urbanization. Trochanteric fractures occur in the younger population due to high velocity trauma, whereas in the elderly population it is most often due to trivial trauma. ${ }^{1}$

Dynamic hip screws (DHS) have been considered as the standard fixation for extra-capsular femoral fracture and yielded good results in the patients with stable intertrochanteric fractures., ${ }^{2,3}$ However, its value for 
comminuted and highly unstable intertrochanteric and sub-trochanteric fractures remains uncertain. High failure rate and excessive impaction have been reported. ${ }^{4-6}$ In addition, the long incision required for the DHS fixation can lead to significant blood loss and soft-tissue damage, which may worsen existing comorbidities in elderly patients. ${ }^{7}$

Proximal femoral fractures are one of the commonest fractures encountered in orthopaedic trauma practice (about 3 lakh per year1 with mortality rate of $4.5 \%-22 \%$ ). Hence the interest in development of improvements in management of these fractures remains high. ${ }^{8,9}$ Extracapsular proximal femoral fractures are those occurring in the region extending from extra-capsular basilar neck region to $5 \mathrm{~cm}$ below lesser trochanter. Proximal femoral fractures include intertrochanteric and sub-trochanteric fractures. ${ }^{10}$

Stable proximal femoral fractures can be managed with conventional implant with predictable results whereas unstable fractures are challenging, and prone to complications. There is a lack of consensus on the treatment for unstable proximal femoral fractures. ${ }^{9}$ Dynamic hip screw (DHS) is commonly used for treating unstable intertrochanteric fractures. Its complications include shortening, medialisation of the distal fragment, implant cut-outs, uncontrolled lateralisation of the proximal fragment, and varus collapse. The proximal femoral locking plate can address these complications of DHS. ${ }^{11}$

Proximal femoral locking compression plate (PFLCP) has been developed recently, which merges locking screw technology with conventional plating techniques. Theoretically, this technique could offer optimum fixation of comminuted and highly unstable fractures that are associated with more shearing and pull-out forces. ${ }^{12,13}$ Several studies have reported success with PFLCP fixation for the treatment of complex femoral fractures and for revision operations after the failure of other implants. ${ }^{14-17}$ Only one small study compared PFLCP and DHS fixation techniques and showed better bone union with the PFLCP fixation in patients with unstable intertrochanteric fracture. ${ }^{11,18}$ However, whether PFLCP is better than other fixation methods remains obscure.

PFLCP provides the surgeon with the flexibility to achieve plate to bone apposition as well as axial compression or angular stability because of three screw fixation at the fracture site. Unlike conventional compression plates, the screw head locks into the PFLCP, thereby creating an angular stable construct. PFLCP can provide a stress shield for the lateral trochanteric wall and prevent lateral migration of proximal fragments. Thus, PF-LCP does not fail at the screw bone interface and provide a strong anchor in osteoporotic bone. The multiple locking screw holes of the PF-LCP provide various options to tackle complex fracture pattern. It functions as an internalized external fixator and minimizes the pressure on the periosteum and encourages biological healing. ${ }^{19,20}$

The purpose of the present study was to compare the outcome of surgical treatment of proximal femoral fracture by dynamic hip screw, proximal femoral nail and proximal femoral locking compression plate.

\section{METHODS}

This prospective comparative observational study was approved by the ethics committee of the hospital. Informed consent of each patient was obtained. Study related data was captured between January 2015 to January 2016 in a tertiary care teaching hospital, Haldia. All the cases presented with intertrochanteric fractures of femur attended orthopedic OPD and emergency department were treated with dynamic hip screw (DHS), proximal femoral nailing (PFN) or proximal femoral locking compression plate were evaluated and followed up. Post-operative X-rays were done to assess reduction and progress of union (non-union/mal-union), any postoperative complications e.g. operative wound infection, implant failure etc. The outcome was assessed based on the postoperative pain, walking ability, hip joint range of motion, and limb length shortening. In all the patients along with personal data, mode of trauma, type of fracture, type of surgery, intra operative \& post-operative complications, follow up examination including hip joint examination, duration of full weight bearing were considered.

Inclusion criteria were patients from age group 18 years and above and both sexes, AO/OTA classification of intertrochanteric fractures of femur and patients presented within two weeks following trauma.

Exclusion criteria were non-operatively treated intertrochanteric fractures of femur, non-union, pathological fractures, fractures associated with polytrauma and patients with previous ipsilateral hip or femur surgeries, patients who are medically unfit for surgery.

\section{Surgical technique}

- Dynamic hip screw (DHS)

- Proximal femoral nail (PFN)

- Proximal femoral locking compression plate (PFLCP)

\section{Measurement of diameter of the nail}

In our study nails of uniform size length i.e. $25 \mathrm{~mm}$ were used in all cases. It was done by taking conventional radiographs of normal femur and by measuring the inner diameter between the cortices at the level of the isthmus of femur was made. We also took help of the ruler provision from the PACS system of $\mathrm{x}$ rays which is used in our hospital. By this technique direct measurement of 
diameter of bone can be made on the computer monitor. However, nails of all sizes were kept ready for operation i.e. $9 \mathrm{~mm}$ to $12 \mathrm{~mm}$ size.

\section{Preoperative planning}

Nail diameter was determined by measuring diameter of the femur at the level of isthmus on an AP X-ray. Neck shaft angle was measured on the unaffected side on an AP X-ray using goniometer. A standard length PFN nail $(250 \mathrm{~mm})$ is used in all our cases.

\section{Operative technique (PFN)}

\section{Patient positioning and fracture reduction}

The patient was placed in supine position on fracture table with adduction of the affected limb by 10 to 150 and closed reduction of the fracture was done by traction and gentle rotation. The unaffected leg was flexed and abducted as far as possible in order to accommodate to image intensifier. The image intensifier was positioned so that anterior- posterior and lateral views of the hip and femur could be taken. The patient was then prepared and draped as for the standard hip fracture fixation. Prophylactic antibiotic was given to all patients 30 minutes before surgery. ${ }^{21}$

\section{Percutaneous fixation of fracture}

In trochanteric fractures we fixed the fracture percutaneously using two " $\mathrm{K}$ " wires which pass along the anterior cortex of greater trochanter and neck of femur into the head of femur. By doing so we can prevent the fracture opening up on adduction of limb for nail insertion. $^{21}$

\section{Approach}

The tip of the greater trochanter was located by palpation in thin patients and in hefty patients we used image intensifier and $5 \mathrm{cms}$ longitudinal incision taken proximal from the tip of the greater trochanter. A parallel incision was made in the fascia lata and gluteus medius was split in line with the fibres. Tip of the greater trochanter is exposed. ${ }^{21}$

Determination of the entry point and insertion of guide wire

In AP view on C-arm, the entry point is on the tip or slightly lateral to the tip of the greater trochanter. In lateral view, guide wire position confirmed in the center of the medullary cavity. The guide wire is inserted in this direction to a depth of $30 \mathrm{cms}$ with a $\mathrm{T}$ handle.

\section{Insertion of the PFN}

After confirming satisfactory fracture reduction an appropriate size nail as determined pre operatively was assembled to the insertion handle and inserted manually as far as possible into the femoral opening. This step was done carefully without hammering by slight twisting movements of the hand until the hole for $8 \mathrm{~mm}$ screw is at the level of inferior margin of neck. In cases where satisfactory reduction was not possible by closed means, open reduction was done. ${ }^{21}$

\section{Insertion of the guide wire for neck screw and hip pin}

These are inserted with the help of the aiming device tightly secured to the insertion handle and using the color coded drill sleeve systems. A $2.8 \mathrm{~mm}$ guide wire was inserted through the drill sleeve after a stab incision with its position in the caudal area of the femoral head for neck screw. A second $2.8 \mathrm{~mm}$ guide wire is inserted through the drill sleeve above the first one for hip pin. ${ }^{21}$

\section{Distal locking}

Distal locking is usually performed with two cortical screws. For standard PFN, aiming was used. Postoperatively, patients pulse, blood pressure, respiration, temperature were monitored. Foot end elevation is given depending on blood pressure. Antibiotics were continued in the post-operative period, I.V for 5 days and oral antibiotics till suture removal (14th day). Analgesics were given as per patients' compliance. Blood transfusion was given depending on the requirement. Sutures removed on $14^{\text {th }}$ postoperative day. All patients were followed up at an interval of 6 weeks till the fracture union is noted and then after once in 3 months till 1year. At every visit patient was assessed clinically regarding hip and knee function, walking ability, fracture union, deformity and shortening. Modified Harris Hip scoring system was used for evaluation. X-ray of the involved hip with femur was done to assess fracture union and implant bone interaction. $^{21}$

\section{Operative technique (DHS)}

Prior to the surgery, radiographs of pelvis with both hips (PBH) in AP and lateral view (side to be operated) was done. The Richard screw (lag screw) length and angle of barrel plate was estimated. Preparation of operative site was done in ward, a day prior to surgery and prophylactic antibiotic IV was given $30 \mathrm{~min}$ before surgery. Spinal/epidural anaesthesia was given in all cases but some required general anaesthesia.

\section{Steps of operation}

After anaesthesia, patient was placed on radiolucent fracture table with buttocks on pelvic rest. Reduction of fracture was done as suggested by Tronzo. Reduction position seen on $\mathrm{C}$-arm image intensifier or the check XRay was taken. Patient's preparation Preoperative scrubbing with savlon and povidone iodine scrub for at least 10 minutes was done and mopped off with spirit. 


\section{Painting and draping}

Painting was done with $5 \%$ povidone iodine and spirit. Draping was done with sterile sheets.

Lateral skin incision was taken from distal edge of greater trochanter. The incision was extended distally for plate application. To determine femoral neck anteversion, a Kirschner wire was passed over the front of femoral neck. Using the appropriate DHS angle guide with ' $T$ 'handle. The K- wire was gently hammered into the head. The DHS angle guide was placed against the middle of femoral shaft and positioned so that the guide tube pointed to the center of femoral head. The lateral cortex was opened with $2 \mathrm{~mm}$ drill bit. The guide wire was inserted into the center of femoral head and advanced to subchondral bone.

The level of insertion of guide wire varies with angle of plate used. The guide wire should lie in middle of the femoral neck in both AP and Lateral views. The direct measuring device was slided over the guide pin and reading of length of pin inside femoral neck and head was taken. The triple reamer was set $10 \mathrm{~mm}$ shorter than the reading of the direct measuring device. The triple reamer was placed over the guide wire and the neck portion was reamed (The DHS triple reamer provides three functions i.e. reaming for the screw for the barrel plate and platebarrel junction. Reamer depth is adjustable in $5 \mathrm{~mm}$ increments).

\section{Richard's screw insertion}

Before inserting a lag screw, a proper size of Richard's screw was measured by direct measuring gauge (a fully inserted lag screw that equals the length determined by direct measuring gauge allows $5 \mathrm{~mm}$ compression when compression screw is used or $5 \mathrm{~mm}$ of fracture collapse before the shaft of the lag screw begins to back out, a $5 \mathrm{~mm}$ shorter lag screw will allow an additional $5 \mathrm{~mm}$ compression). To insert the screw into head and neck the coupling screw guide shaft and the hip screw were assembled. $^{21}$

\section{Operative technique (PFLCP)}

Preoperative investigations and anesthesia fitness was done prior to the surgery similar to that as in proximal femoral nailing and DHS fixation. Prior to the surgery, radiographs of pelvis with both hips $(\mathrm{PBH})$ in $\mathrm{AP}$ and lateral view (of site to be operated) was done. Length of the plate was estimated.

\section{Steps of operation}

After anesthesia patient was placed on radiolucent fracture table with buttocks on pelvic rest. Reduction of fracture was done as suggested by Tronzo. Type 2 fracture reduced with traction only. Type 3 fracture reduced by first giving traction and $20^{\circ}$ abduction to correct varus deformity and then the limb was externally rotated gently and finally internally rotated upto neutral position. Type 4 fracture was reduced by DimonHughston medial displacement osteotomy. Type 5 fracture was fixed by notching out the shaft fragment so that the neck can be jammed into for stabilization. Reduction position seen on image intensifier or the check $\mathrm{X}$ ray was taken.

The vastus lateralis splitting approach was used. Lateral skin incision was taken from distal edge of the greater trochanter. Subcutaneous tissue tensor fascia lata were cut in the same line and vastus lateralis was split from trochanteric crest to expose the greater trochanter and upper of shaft upto 2 inches. The incision was extended proximally upto the tip of the greater trochanter. The incision was extended distally for plate application. The plate was held by means of screw jig on the lateral surface of the femur along the greater trochanter and proximal shaft of femur. K-wires/guide-wires were fixed in the given holes of the plate in the trochanteric area locking cancellous screws were placed along the pregrooved holes. Three proximal screw holes are at the following angles of plate shaft: A) First proximal hole $95^{\circ}$ B) Second proximal hole $-120^{\circ}$ C) Third proximal hole $-135^{\circ}{ }^{21}$

\section{Follow up protocol}

Patient was called for follow-up every month. On follow up following points were noted: complaints of pain if any, deformity, shortening, range of hip and knee movements, ability to squat and sit cross legged, walking ability with or without support and whether the patient returns to pre-injury occupation.

X-ray pelvis with both hip AP view and lateral view of operated hip were looked for: signs of union, neck - shaft angle, failure of fixation, failure of implant, reaction to metal.

Functional results were assessed based following hip scoring system adopted. The analysis was carried out using IBM SPSS software package V.22 with descriptive statistics.

\section{RESULTS}

This was a prospective comparative study of the treatment of 60 cases of trochanteric and peritrochanteric fractures of proximal femur proximal femoral nail, dynamic hip screw and proximal femoral locking compression plate in the department of orthopaedics and emergency department of a tertiary care teaching hospital, West Bengal. Study related data were captured between January 2015 to January 2016.

In our series, majority of the cases i.e. 22 [36.66\%] were seen in the age group of 41-60 years and 60-80 years as 
given in Table 1. Mean age in years of patients treated with PFN, DHS, and PFLCP were 55.9, 59.8 and 61 years respectively. Youngest patient was 29 years old while the oldest was 83 years old in the study. Most of patients from present study were males as in Table 1. Majority of cases road traffic accidents were main reason, which was followed by domestic fall as shown in Table 1. Total $06(30 \%)$ cases of intertrochanteric fractures seen amongst 20 cases treated by PFN and $16(80 \%)$ cases of intertrochanteric fractures seen amongst 20 cases treated by DHS and $14(70 \%)$ of sub-trochanteric fractures amongst 20 cases of proximal femoral fractures were fixed by PFLCP as in Table 1.

Left sided inter-trochanteric fractures were more common in PFN and DHS groups in comparison to PFLCP as given in Table 2.

Table 1: Demographic and other characteristics of study participants.

\begin{tabular}{|c|c|c|c|}
\hline Variables & No. of patients in PFN [n=20] & No. of patients in DHS [ $n=20]$ & No. of patients in PFLCP $[\mathrm{n}=20]$ \\
\hline \multicolumn{4}{|l|}{ Age (Years) } \\
\hline $20-40$ & $4(20 \%)$ & $4(20 \%)$ & $3(15 \%)$ \\
\hline $41-60$ & $6(30 \%)$ & $7(35 \%)$ & $9(45 \%)$ \\
\hline $61-80$ & $8(40 \%)$ & $8(40 \%)$ & $6(30 \%)$ \\
\hline Above 80 & $2(10 \%)$ & $1(5 \%)$ & $2(10 \%)$ \\
\hline \multicolumn{4}{|l|}{ Sex } \\
\hline Male & $18(90 \%)$ & $15(75 \%)$ & $17(85 \%)$ \\
\hline Female & $02(10 \%)$ & $05(20 \%)$ & $03(15 \%)$ \\
\hline \multicolumn{4}{|c|}{ Mode of trauma } \\
\hline $\begin{array}{l}\text { Road traffic } \\
\text { accident }\end{array}$ & $09(45 \%)$ & $13(65 \%)$ & $11(55 \%)$ \\
\hline $\begin{array}{l}\text { Domestic fall } \\
\text { (fall at home) }\end{array}$ & $11(55 \%)$ & $6(30 \%)$ & $7(35 \%)$ \\
\hline Assault & $0(0 \%)$ & $01(05 \%)$ & $02(10 \%)$ \\
\hline \multicolumn{4}{|l|}{ Side of Injury } \\
\hline Left & $13(65 \%)$ & $6(30 \%)$ & $12(60 \%)$ \\
\hline Right & $07(35 \%)$ & $14(70 \%)$ & $08(40 \%)$ \\
\hline \multicolumn{4}{|c|}{ Type of facture } \\
\hline $\begin{array}{l}\text { Inter } \\
\text { trochanteric }\end{array}$ & $06(30 \%)$ & $16(80 \%)$ & $06(30 \%)$ \\
\hline $\begin{array}{l}\text { Sub } \\
\text { trochanteric }\end{array}$ & $14(70 \%)$ & $04(20 \%)$ & $14(70 \%)$ \\
\hline
\end{tabular}

Table 2: Type of fractures and side of injury in present study participants.

\begin{tabular}{|c|c|c|c|c|c|c|}
\hline Type of fracture & \multicolumn{2}{|c|}{ PFN [n=20] } & \multicolumn{2}{|c|}{ DHS [n=20] } & \multicolumn{2}{|c|}{ PFLCP [n=20] } \\
\hline & Left & Right & Left & Right & Left & Right \\
\hline Inter-trochanteric & $6(30 \%)$ & $3(15 \%)$ & $7(35 \%)$ & $6(30 \%)$ & $4(20 \%)$ & $6(30 \%)$ \\
\hline Sub-trochanteric & $6(30 \%)$ & $5(35 \%)$ & $5(25 \%)$ & $2(10 \%)$ & $5(25 \%)$ & $5(25 \%)$ \\
\hline Total & 12 & 8 & 12 & 8 & 09 & 11 \\
\hline
\end{tabular}

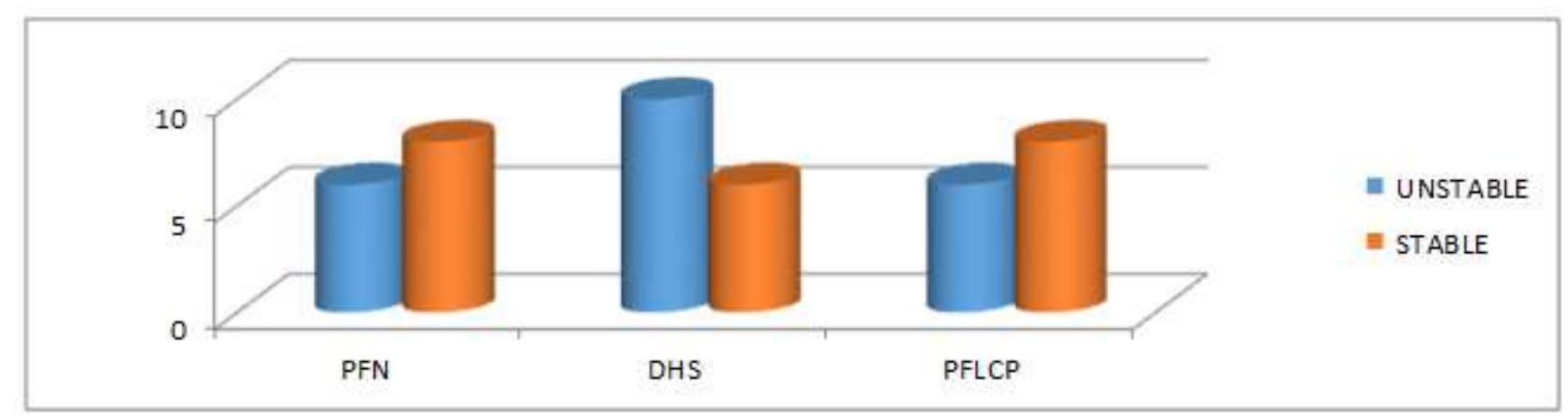

Figure 1: Stability pattern of intertrochanteric fractures. 
Table 3: Time duration for surgery in the present study.

\begin{tabular}{|llll|}
\hline Time duration for surgery (Days) & PFN & DHS & PFLCP \\
\hline $\mathbf{0 - 5}$ & $08(40 \%)$ & $06(30 \%)$ & $03(15 \%)$ \\
\hline $\mathbf{5 - 1 0}$ & $07(35 \%)$ & $11(55 \%)$ & $09(45 \%)$ \\
\hline $\mathbf{1 0 - 1 5}$ & $03(15 \%)$ & $02(10 \%)$ & $06(30 \%)$ \\
\hline $\mathbf{1 5 - 2 0}$ & $02(10 \%)$ & $01(5 \%)$ & $02(10 \%)$ \\
\hline Total & 20 & 20 & 20 \\
\hline
\end{tabular}

Table 4: Length of proximal screws used PFN in the present study.

\begin{tabular}{|lllll|}
\hline $\begin{array}{l}\text { Screw Length (in } \\
\mathbf{m m})\end{array}$ & $\begin{array}{l}\text { Cases with length of screw used as ante } \\
\text { rotation screw }(\mathbf{6 . 4} \mathbf{~ m m})\end{array}$ & $\begin{array}{l}\text { Cases with length of screw used as lag } \\
\text { screw }(\mathbf{7 . 9} \mathbf{~ m m})\end{array}$ \\
\hline & No. of cases & Percentage & No. of cases & Percentage \\
\hline $\mathbf{5 0}$ & 0 & 00 & 0 & 00 \\
\hline $\mathbf{5 5}$ & 0 & 00 & 0 & 00 \\
\hline $\mathbf{6 0}$ & 0 & 00 & 0 & 00 \\
\hline $\mathbf{6 5}$ & 2 & 10 & 0 & 00 \\
\hline $\mathbf{7 0}$ & 4 & 20 & 0 & 00 \\
\hline $\mathbf{7 5}$ & 5 & 25 & 3 & 15 \\
\hline $\mathbf{8 0}$ & 8 & 40 & 3 & 15 \\
\hline $\mathbf{8 5}$ & 1 & 05 & 9 & 45 \\
\hline $\mathbf{9 0}$ & 0 & 00 & 3 & 15 \\
\hline $\mathbf{9 5}$ & 0 & 00 & 2 & 10 \\
\hline $\mathbf{1 0 0}$ & 0 & 00 & 0 & 00 \\
\hline $\mathbf{1 0 5}$ & 0 & 00 & 0 & 00 \\
\hline $\mathbf{1 1 0}$ & 0 & 00 & 0 & 00 \\
\hline $\mathbf{1 1 5}$ & 0 & 00 & 0 & 00 \\
\hline Total & 20 & 100 & 20 & 100 \\
\hline
\end{tabular}

Duration of surgery was more in cases of subtrochanteric fractures when compared to trochanteric fractures and in fractures where we had to do open reduction. Majority of patients in present study series were operated within 10 days following admission in hospital (44/60) as shown in Table 3. But in some patients (16/60) operative procedure was delayed due to medical problems (hypertension and uncontrolled diabetes). Average mean time lapse for surgery was 6.85 days.

In present study series we have used leg screw in range of $75 \mathrm{~mm}$ to $115 \mathrm{~mm}$ as in Table 4. Amongst them, in 3 cases each $(15 \%)$ we have used $75 \mathrm{~mm}$ and $80 \mathrm{~mm}$ screw. In 9 cases $(45 \%) 85 \mathrm{~mm}$ screw, 3 cases (15\%) $90 \mathrm{~mm}$ screw and in 2 cases $(10 \%)$ we have used $95 \mathrm{~mm}$ screw. Anti rotation screw or hip pin screw was used in range of $65-80 \mathrm{~mm}$ dimensions. In 2 cases $(10 \%) 65 \mathrm{~mm}$, in 4 cases $(20 \%) 70 \mathrm{~mm}$, in 5 cases $(25 \%) 75 \mathrm{~mm}$ and in 8 cases $(40 \%) 80 \mathrm{~mm}$ screws were used respectively as shown in Table 4.

Length of Richard's screw (lag screw) used in DHS were in the range of $65 \mathrm{~mm}$ to $100 \mathrm{~mm}$ length. Amongst them, 1 case $(5 \%) 65 \mathrm{~mm}, 3$ cases $(15 \%) 70 \mathrm{~mm}, 1$ cases $(5 \%)$ $75 \mathrm{~mm}$, in 6 cases $(30 \%) 80 \mathrm{~mm}$, in 4 cases $(20 \%) 85$ $\mathrm{mm}$, in 3 cases $(15 \%) 90 \mathrm{~mm}$ screw was used respectively as given in Table 5. Associated injuries mainly fracture lower end radius and fracture calcaneum were presented in Table 7. Local infection and superficial wound infections were more common among the postoperative complications. Some patients though less developed chest infection and UTIs as shown in Table 8. The patients who had urinary traction infection, was due to prolonged catheterization. Appropriate treatment in the form of antibiotics was given based on sensitivity study.

Table 5: Length of proximal screws used DHS in the present study.

\begin{tabular}{|lll|}
\hline Lag screw length (in mm) & No. of cases & Percentage \\
\hline $\mathbf{5 0}$ & 0 & 00 \\
\hline $\mathbf{5 5}$ & 0 & 00 \\
\hline $\mathbf{6 0}$ & 0 & 00 \\
\hline $\mathbf{6 5}$ & 1 & 05 \\
\hline $\mathbf{7 0}$ & 3 & 15 \\
\hline $\mathbf{7 5}$ & 1 & 05 \\
\hline $\mathbf{8 0}$ & 6 & 30 \\
\hline $\mathbf{8 5}$ & 4 & 20 \\
\hline $\mathbf{9 0}$ & 3 & 15 \\
\hline $\mathbf{9 5}$ & 1 & 05 \\
\hline $\mathbf{1 0 0}$ & 1 & 05 \\
\hline $\mathbf{1 0 5}$ & 0 & 00 \\
\hline $\mathbf{1 1 0}$ & 0 & 00 \\
\hline $\mathbf{1 1 5}$ & 0 & 00 \\
\hline Total & 20 & 100 \\
\hline
\end{tabular}


Table 6: Hole plate used PFLCP in the present study.

\begin{tabular}{|lll|}
\hline No. of hole plate & No. of cases & Percentage \\
\hline $\mathbf{5}$ & 4 & 20 \\
\hline $\mathbf{6}$ & 3 & 15 \\
\hline $\mathbf{7}$ & 7 & 35 \\
\hline $\mathbf{8}$ & 5 & 25 \\
\hline $\mathbf{9}$ & 1 & 05 \\
\hline $\mathbf{1 0}$ & - & - \\
\hline Total & 20 & 100 \\
\hline
\end{tabular}

External rotation of $15^{\circ}$ was noticed in 02 cases (10\%) operated by PFN. Postoperatively the angle was measured and compared to the normal side to assess the correction achieved. Varus deformitity was noted in one case $(5 \%)$ as in Table 9 . It might be seen due to early backing out of screws.

In present study, the cases that we had operated by PFN, not encountered ' $Z$ ' effect while in 03 cases (15\%) we have found reverse ' $Z$ ' effect. One case $(5 \%)$ nail was broken at site in between proximal screws \& distal lock as given in Table 11 .

Table 7: Associated injuries in the study participants.

\begin{tabular}{|llll|}
\hline Injuries & No. of patients & No. of patients & No. of patients \\
\hline Head injuries & PFN [n=20] & DHS $[\mathrm{n}=20]$ & PFLCP [n=20] \\
\hline Blunt abdominal injury & 00 & $03(15 \%)$ & 00 \\
\hline Blunt chest trauma & $01(5 \%)$ & 00 & 00 \\
\hline $\begin{array}{l}\text { Fracture lower end } \\
\text { radius }\end{array}$ & $02(10 \%)$ & 00 & $01(5 \%)$ \\
\hline Fracture calcaneum & $03(15 \%)$ & $01(5 \%)$ & $03(15 \%)$ \\
\hline Total & 07 & $01(5 \%)$ & $01(5 \%)$ \\
\hline
\end{tabular}

Table 8: Complications observed in the present study.

\begin{tabular}{|llll|}
\hline Complications & $\begin{array}{l}\text { No.of patients in PFN } \\
{[\mathbf{n = 2 0 ]}}\end{array}$ & $\begin{array}{l}\text { No.of Patients } \\
\text { in DHS [n=20] }\end{array}$ & $\begin{array}{l}\text { No.of patients in } \\
\text { PFLCP [n=20] }\end{array}$ \\
\hline Systemic complications & 0 & 0 & 0 \\
\hline Chest infection & $1(5 \%)$ & 0 & $1(5 \%)$ \\
\hline Pulmonary embolism & 0 & 0 & 0 \\
\hline Respiratory distress & $1(5 \%)$ & 0 & 0 \\
\hline Urinary tract infection & $1(5 \%)$ & $1(5 \%)$ & 0 \\
\hline Urinary retention & $2(10 \%)$ & $2(10 \%)$ & 0 \\
\hline Deep vein thrombosis & 0 & 0 & $3(15 \%)$ \\
\hline Local complication & $3(15 \%)$ & $2(10 \%)$ & $4(20 \%)$ \\
\hline $\begin{array}{l}\text { Superficial wound } \\
\text { infection }\end{array}$ & $2(10 \%)$ & $2(10 \%)$ & $1(5 \%)$ \\
\hline Deep wound infection & $1(5 \%)$ & 0 & 0 \\
\hline Death & 0 & 0 & \\
\hline
\end{tabular}

Table 9: Rotational malalignment in the study participants.

\begin{tabular}{|llll|}
\hline & No. of patients in PFN & No. of patients in DHS & No. of patients in PFLCP \\
\hline External rotation & $02(10 \%)$ & $01(5 \%)$ & $02(10 \%)$ \\
\hline Internal rotation & 0 & 0 & 0 \\
\hline Varus deformity of hip & $01(5 \%)$ & $03(15 \%)$ & $02(10 \%)$ \\
\hline Valgus deformity & 0 & 0 & 0 \\
\hline Shortening & $01(5 \%)$ & $3(15 \%)$ & $02(10 \%)$ \\
\hline
\end{tabular}

\section{DISCUSSION}

Intertrochanteric fractures occur in people with poor bonequality, about half of the intertrochanteric fractures are comminuted and unstable. In these fractures, excessive medialization of the shaft and subsequent loss of contact between the fragments can lead to fixation failure. Even after the fracture ultimately unites, limb shortening and decreased length of the abductor lever arm adversely affect hip function. Therefore unstable hip fractures should be differentiated from their stable counterparts with regard to treatment plan and prognosis. ${ }^{9}$ The locking compression plate was introduced in the $21^{\text {st }}$ century as a new implant that allows angular stable 
plating for the treatment of complex comminuted and osteoporotic fractures. The locking compression plate (LCP) has the option of using the dynamic compression hole or the threaded locking hole or both. This combination provides the flexibility of cortex screw or locking screw fixation. ${ }^{22-25}$ More recently, locking plates especially designed for the proximal femur, PF-LCP have become available especially for the management of complex trochanteric fractures. ${ }^{26}$

Table 10: Implant related intraoperative complications among study participants in different procedures.

\begin{tabular}{|lll|}
\hline Groups and intraoperative complications & No. of patients & Percentage \\
\hline PFN [n=20] & 5 & 25 \\
\hline Ill-fitting jig & 01 & 05 \\
\hline Impropriate length of proximal screws & 01 & 05 \\
\hline Difficulty in distal locking & 00 & 0 \\
\hline Fracture of greater trochanter & 00 & 0 \\
\hline Fracture below tip of nail & 00 & 0 \\
\hline Revision surgery & & \\
\hline DHS [n=20] & 1 & 5 \\
\hline Difficulty in Reduction & 2 & 10 \\
\hline Shattering of Lateral Cortex & 0 & 0 \\
\hline Fracture below the plate & 0 & 0 \\
\hline Breakage of plate & 01 & 5 \\
\hline Breakage of screw & & \\
\hline PFLCP [n=20] & 2 & 10 \\
\hline Difficulty in Reduction & 1 & 5 \\
\hline Shattering of Lateral Cortex & 1 & 5 \\
\hline Fracture below the plate & 0 & 0 \\
\hline Breakage of plate & 0 & 0 \\
\hline Breakage of screw & & \\
\hline
\end{tabular}

Table 11: Radiological complications encountered (postoperatively).

\begin{tabular}{|c|c|c|}
\hline Groups and postoperative complications & No. of patients & Percentage \\
\hline \multicolumn{3}{|l|}{ PFN [n=20] } \\
\hline Cut out of neck screw & 01 & 5 \\
\hline $\mathrm{Z}$ effect & 00 & 0 \\
\hline Reverse $\mathrm{Z}$ effect & 03 & 15 \\
\hline Breakage of nail & 01 & 5 \\
\hline Bolt breakage & 00 & 0 \\
\hline \multicolumn{3}{|l|}{ DHS [n=20] } \\
\hline Excessive Lag Screw back out & 1 & 5 \\
\hline Plate breakage & 0 & 0 \\
\hline Cortical screw loosening & 1 & 5 \\
\hline Cortical Screw breakage/ bending & 0 & 0 \\
\hline \multicolumn{3}{|l|}{ PFLCP $[\mathrm{n}=20]$} \\
\hline Trochanteric cancellous screw loosening & 1 & 5 \\
\hline Plate breakage & 0 & 0 \\
\hline Cortical screw loosening & 3 & 15 \\
\hline Cortical screw breakage/bending & 2 & 10 \\
\hline
\end{tabular}

PF-LCP acts as a fixed angle internal fixator device and achieves greater stability compared with DHS/DCS/angle blade plate while avoiding excessive bone removal. It is also ideal in osteoporotic bones. PF-LCP prevents rotational instability and allows angular stability by creating a fixed angle block for treatment of complex, comminuted proximal femoral fractures. 5 proximal locking screws (5 mm, non-cannulated) provide an angular stable construct independent of bone quality. ${ }^{9}$

The goal of treatment for is to achieve the stability and early mobilization. The successful restoration of stability and early mobilization reduce the morbidity and mortality rates associated with prolonged immbolization. ${ }^{27}$ The 
treatment goal is to achieve anatomic reduction with a stable fracture fixation to allow early functional rehabilitation. Over the past decades, intertrochanteric and sub-trochanteric fractures were predominantly treated by dynamic hip screw. ${ }^{28}$ However, the complication rate for unstable fractures treated with a dynamic hip screw or dynamic condylar screw plate has shown to be as high as $3 \%$ to $26 \% .^{29}$ Primary or secondary varus collapse and hardware failure by "cut out" of the femoral head screw are the most frequently reported complications. ${ }^{30}$ Although the DHS is one of the standard treatments, high failure rate is reported in unstable fracture. ${ }^{31-33}$

Saarenpa et al reported that there operation rate is $8.2 \%{ }^{31}$ Intramedullary devises, such as the gamma nail (GN), PFN have same theoretical advantage over the DHS, because they do not depend on the screw fixation of a plate to the lateral cortex, which can be worry part in osteoporotic bone along a more medial axis. Wanq et al compare the clinical outcomes of DHS, IF and PFLCP in the elderly patients and concluded that PFLCP is the credible method in the elderly patients, especially for severe comminuted fracture and osteoporotic bone. ${ }^{34}$ Guo Chun et al reported that treatment with PFLCP can provide good to excellent healing for pertrochantric femoral fracture, with a limited occurrence of complication. $^{35}$

In the study we aimed to evaluate whether these theoretical advantages could be proved in practice, by a comparison of the results of PFN, DHS and PFLCP implants. In our study, we found that PFNs prove to be more useful in difficult fractures with a sub-trochanteric extension or reversed obliquity. The rotational stability was higher when proximal femoral nail is used in these fractures. The incidence of wound infection was found to be lower with intramedullary implants which resulted in early ambulation of the patients. A central position of screw is probably optimal for pertrochanteric fractures. We found that screw of PFN proved more likely to go up the central axis of the femoral neck. This is in coherence with findings of previous studies. Non-union of trochanteric fracture although is a rare. However, no case was found in our series of patients. We did not encounter any secondary femoral fracture in patients managed by proximal femoral nails though this is one of common complication reported in some previous studies. The fractures which were severely comminuted where treated better with the DHS device and PFLCP device as compared to PFN. The implant related complications were much lesser in the patients treated with DHS and mostly with PFLCP. However, the rate of union was similar in three groups (PFN and DHS and PFLCP). All the implants in their own right are excellent modalities in the management of pertrochanteric fractures of the femur. It is observed that of all proximal femoral fractures intertrochanteric fractures along with peritrochanteric fractures with severe comminutions were treated best with DHS. Sub-trochanteric fractures and reverse oblique fractures with rotational mal-alignment issues were treated best by PFN. Sub-trochanteric and peritrochanteric femur fractures especially with increased communition do provide an alternative to be fixed by PFLCP.

Further studies with large number of patients and long term follow up is needed to determine the optimal implant for the internal fixation of pertrochantric femoral fractures.

\section{CONCLUSION}

In the present study, there were 20 patients operated by PFN, 20 patients operated by DHS and 20 patients operated by PFLCP. The advantage with PFN is that smaller exposure is required than for a sliding screw, it may therefore be associated with lesser blood loss, shorter operating time and less morbidity. In fractures managed by closed intramedullary nailing, incidence of mal-rotation and deformity is found to be lower as compared to those with PFLCP and DHS. We found that PFNs prove to be more useful in difficult fractures with a sub-trochanteric extension or reversed obliquity. The incidence of wound infection was found to be lower with intramedullary implants. The implant related complications were much lesser in the patients treated with DHS and mostly with PFLCP. It is observed that of all proximal femoral fractures intertrochanteric fractures along with peritrochanteric fractures with severe comminutions were treated best with DHS. Subtrochanteric fractures and reverse oblique fractures with rotational malalignment issues were treated best by PFN. Subtrochanteric and perictrochanteric femur fractures especially with increased communition do provide an alternative to be fixed by PFLCP.

In our study, the mean blood loss was comparatively less in patients managed by PFN fixation as compared to the DHS fixation and PFLCP fixation. The implant related complications were much lesser in the patients treated with DHS and mostly with PFLCP. The rate of union was similar in three groups.

Funding: No funding sources

Conflict of interest: None declared

Ethical approval: The study was approved by the institutional ethics committee

\section{REFERENCES}

1. Ozkan K, Türkmen I, Sahin A, Yildiz Y, Erturk S, Soylemez MS. A biomechanical comparison of proximal femoral nails and locking proximal anatomic femoral plates in femoral fracture fixation: A study on synthetic bones. Indian $\mathrm{J}$ Orthop. 2015;49:347-51.

2. Butler M, Forte M, Kane RL, Joglekar S, Duval SJ, Swiontkowski M, et al. Treatment of common hip fractures. Evid Rep Technol Assess (Full Rep). 2009;184:1-85. 
3. Saudan M, Lubbeke A, Sadowski C, Riand N, Stern R, Hoffmeyer P. Pertrochanteric fractures: is there an advantage to an intramedullary nail? A randomized, prospective study of 206 patients comparing the dynamic hip screw and proximal femoral nail. J Orthop Trauma. 2002;16:386-93.

4. Lunsjo K, Ceder L, Tidermark J, Hamberg P, Larsson BE, Ragnarsson B, et al. Extramedullary fixation of 107 sub-trochanteric fractures: a randomized multicenter trial of the medoff sliding plate versus 3 other screw-plate systems. Acta Orthop Scand. 1999;70:459-66.

5. Setiobudi T, Ng YH, Lim CT, Liang S, Lee K, Das De S. Clinical outcome following treatment of stable and unstable intertrochanteric fractures with dynamic hip screw. Ann Acad Med Singapore. 2011;40:482-7.

6. Oger P, Katz V, Lecorre N, Beaufils P. Fracture of the great trochanter treated by dynamic hip screw plate: measure of impaction according to fracture type. Rev Chir Orthop. 1998;84:539-45.

7. Morris AH, Zuckerman JD. National consensus conference on improving the continuum of care for patients with hip fracture. J Bone Joint Surg Am. 2002;84:670-4.

8. Ehmke LW, Fitzpatrick DC, Krieg JC, Madey SM, Bottlang M. Lag screws for hip fracture fixation: evaluation of migration resistance under simulated walking. J Orthop Res. 2005;23:1329-35.

9. Kumar N, Kataria H, Yadav C, Gadagoli BS, Raj R. Evaluation of proximal femoral locking plate in unstable extracapsular proximal femoral fractures: Surgical technique \& mid-term follow up results. J Clin Orthop Trauma. 2014;5(3):137-45.

10. Russel TA. Intertrochanteric fractures. In: Bucholz RW, Heckman JD, Court-Brown CM, Tornetta P 3rd, editors. Rockwood and Green's fractures in adults. 7th edition. 2009: 1597-1640.

11. Dhamangaonkar AC, Joshi D, Goregaonkar AB, Tawari AA. Proximal femoral locking plate versus dynamic hip screw for unstable intertrochanteric femoral fractures. J Orthop Surg (Hong Kong). 2013;21(3):317-22.

12. Frigg R. Development of the locking compression plate. Injury. 2003;34(2):6-10.

13. Wagner M. General principles for the clinical use of the LCP. Injury. 2003;34(2):31-42.

14. Sommer C, Gautier E, Muller M, Helfet DL, Wagner M. First clinical results of the locking compression plate (LCP). Injury. 2003;34(2):43-54.

15. Zha GC, Chen ZL, Qi XB, Sun JY. Treatment of pertrochanteric fractures with aproximal femur locking compression plate. Injury. 2011;42:1294-9.

16. Hasenboehler EA, Agudelo JF, Morgan SJ, Smith WR, Hak DJ, Stahel PF. Treatment of complex proximal femoral fractures with the proximal femur locking compression plate. Orthopedics. 2007;30:618-23.

17. Oh CW, Kim JJ, Byun YS, Oh JK, Kim JW, Kim $\mathrm{SY}$, et al. Minimally-invasive plate osteosynthesis of sub-trochanteric femur fractures with a locking plate: a prospective series of 20 fractures. Arch Orthop Trauma Surg. 2009;129:1659-65.

18. Zhong B, Zhang Y, Zhang C, Luo CF. A comparison of proximal femoral locking compression plates with dynamic hip screws in extracapsular femoral fractures. Orthop Traumatol Surg Res. 2014;100(6):663-8.

19. Govindasamy R, Gnanasundaram R, Kasirajan S, Meleppuram JJ, Archit K. Proximal femur locking compression plate in complex proximal femoral fractures: a retrospective analysis. Int J Res Orthop. 2016;2:104-8.

20. Egol KA, Kubiak EN, Fulkerson E, Kummer FJ, Koval KJ. Biomechanics of locked plates and screws. J Orthop Trauma. 2004;18(8):488-93.

21. Canale TS. Campbell's operative orthop. Volume 3. 9th edition. 1998: 218.

22. Koval KJ, Zuckerman JD. Hip fractures: II. Evaluation and treatment of intertrochanteric fractures. J Am Acad Orthop Surg. 1994;2:150-6.

23. Wieser K, Babst R. Fixation failure of the LCP proximal femoral plate $4.5 / 5.0$ in patients with missing posteromedial support in unstable per-, inter-, and subtrochanteric fractures of the proximal femur. Arch Orthop Trauma Surg. 2010;130:1281-7.

24. Haidukewych GJ, Israel TA, Berry DJ. Reverse obliquity fractures of the intertrochanteric region of the femur. J Bone Joint Surg Am. 2001;83:643-50.

25. Sadowski C, Lubbeke A, Saudan M, Riand N, Stern $\mathrm{R}$, Hoffmeyer P. Treatment of reverse oblique and transverse intertrochanteric fractures with use of an intramedullary nail or a 95_ screw-plate: a prospective, randomized study. J Bone Joint Surg Am. 2002;84:372-81.

26. Forte ML, Virnig BA, Kane RL, Durham S, Bhandari M, Feldman R, et al. Geographic variation in device use for intertrochanteric hip fractures. J Bone Joint Surg Am. 2008;90:691-9.

27. Simpson AH, Varty K, Dodd CA. Sliding hip screws: modes of failure. Injury. 1989;20(4):227-31.

28. Babhulkar SS. Management of trochanteric fractures. Indian J Orthop. 2006;40(4):210-8.

29. Yong CK, Tan CN, Penafort R, Singh DA, Varaprasad MV. Dynamic Hip Screw Compared to Condylar Blade Plate in the Treatment of Unstable Fragility Intertrochanteric Fractures. Malaysian Orthop J. 2009;3(1):13-8.

30. Kim WY, Han CH, Park JI, Kim JY. Failure of intertrochanteric fracture fixationwith a dynamic hip screw in relation to pre-operative fracture stability andosteoporosis. Int Orthop. 2001;25:360-2.

31. Saarenpaa I, Heikkinen T, Ristiniemi J. Functional comparison of the dynamic hip screw and the gamma locking nail in trochanteric hip fractures: a matched pair study of 268 patients. Int Orthop. 2009;33(1):255-60.

32. Fogagnolo F, KfuriJr M, Paccola C. Intramedullary fixation of pertrochanteric hip fractures with the 
short AO-ASIF proximal femoral nail. Arch Orthop Trauma Surg. 2004;124:31.

33. Pajarinen J, Lindahl J, Michelsson O, Savolainen V, Hirvensalo E, et al. Pertrochanteric femoral fractures treated with a dynamic hip screw or a proximal femoral nail. A randomised study comparing post-operative rehabilitation. J Bone Joint Surg Brit. 2005;87:76-81.

34. Wang Y, Yang YY, Yu ZH, Li CQ, Wu YS, Zheng $\mathrm{XX}$. Comparative study of intertrochanteric fractures treated with proximal femur locking compress plate in aged. ZhongguoGu Shang. 2011;24:370-3.
35. Guo-Chun Zha. Treatment of pertrochnatric fractures with proximal femur locking compression plate. Injury. 2011;42:1294-9.

Cite this article as: Veeragandham $\mathrm{P}$, Sahu RK, Misra $\mathrm{S}$. Comparative study between proximal femoral nailing and dynamic hip screw with proximal femoral locking compression plates in intertrochanteric fracture of femur. Int J Res Orthop 2017;3:339-49. 